\title{
Groundwater modelling using an analytic element method and finite difference method: An insight into Lower Ganga river basin
}

\author{
Padam Jee Omar*, Shishir Gaur, S B Dwivedi and P K S Dikshit \\ Department of Civil Engineering, Indian Institute of Technology (BHU), Varanasi, India. \\ *Corresponding author.e-mail: sss.padam.omar@gmail.com
}

MS received 10 December 2018; revised 2 May 2019; accepted 6 May 2019; published online 10 July 2019

Groundwater flow modelling provides the water flow dynamics for the estimation and prediction of groundwater movement and its condition in the aquifer. The modelling helps for the management of the groundwater resources under various hydrological and anthropogenic stresses. In this paper, a modelling exercise was performed using the analytic element method (AEM) and finite difference method (FDM) for the part of Ganga river basin which includes the Varanasi district. Further compression was performed to understand the limitations and benefits of both AEM and FDM based on ease of model development, data requirement and their performances. The groundwater model was developed for the transient state condition based on data for the year 2004-2017. The results show that for most of the observed wells, the difference between the observed head and the simulated head is found in the $90 \%$ confidence level. It is found that the AEM does not require a fixed boundary condition which makes the development of the conceptual model less complicated. In the FDM, pumping wells are approximately located and averaged over the cell which becomes a cause of the inaccurate location of the wells. It is found that model development in the AEM is less complicated compared to the FDM. It can be concluded that in some cases AEM-based modelling is more accurate as compared to FDM-based flow modelling. This study can be very helpful for groundwater professionals in deciding the best suitable method for their study area and to avoid the complexity of the model.

Keywords. Groundwater modelling; AEM; FDM; GIS; Varanasi.

\section{Introduction}

Groundwater has become a major source of drinking water because of the high contamination in the surface water like the Ganga river in Varanasi and the surrounding areas. The excessive and unplanned extraction of groundwater is becoming the main reason for the depletion of groundwater in the different parts of the country. The groundwater management includes an efficient and effective management of groundwater resources at both quantity and quality levels (Gorelick 1984; Omar et al. 2017).

For this purpose, researchers have developed many groundwater models and proposed different modelling techniques. In the literature, there are two approaches adopted: one is a grid-based numerical method and second is an analytical method. The grid-based plan consists of the finite difference method (FDM) and finite element method (FEM) of the modelling. The numerical methods of modelling required extensive input 
data, and the accuracy of results depends on the input data, the size of space and time discretisation along with the numerical method used to solve the model equations (Bakker et al. 1999). The key function of the analytic element model is that they do not need the discretisation of the internal model domain into cells or elements as in the case of the numerical method. The analytic element model is defined by 'analytic elements' representing line sources and sinks such as rivers and drains or specified head and specified flow boundaries (Bandilla et al. 2007). The wells are also represented as points, and recharge and aquifer properties can be defined on polygons.

In the grid-based methods, pumping wells are approximately located and averaged over the cell of a grid which become a cause of the inaccurate location of wells (Bennett 1976). While in the AEM, wells are directly placed at their exact coordinates (Matott et al. 2006). In the literature, there is so much focus on the mathematical theory of the AEM, but practical models need to be implemented (Strack 1989, 1999, 2003; Haitjema et al. 2000; Kraemer et al. 2004). Particularly, groundwater modelling for the large regions where coarse grids are used, it becomes the cause of considerable error in solutions (Hunt et al. 1998). A comparative study of the FDM and AEM was conducted for the Amsterdam city water supplies. The study suggested that the AEM is more capable on some condition than the FDM. As in the FDM, the whole system should be solved and the head values at each cell should be computed to get the groundwater head values even at a single cell, which in turns increases the computational time (Olsthoorn 1999). Strack (1999) developed a steady-state groundwater model using the AEM and constant aquifer properties. Later, he added this method to the rotational and transient conditions of the groundwater flow. If sufficient information about the boundary condition of the area is not available, the AEM is preferred because the method does not need the exact boundary condition around the area (Csoma 2001). A new analytic element formulation was presented by Bakker (2004) for a transient, periodic DupuitForchheimer flow. For large-scale groundwater flow modelling, a new algorithm was developed by Bandilla et al. (2007). This new algorithm computes fluxes of all features at the start of iteration thus improves the convergence of the head specied element model. AnAqSim has powerful capabilities for the development of a rapid model under multi-layer, anisotropic, transient conditions. It can import complex base map graphics to make it easier in the development of the AEM model and has the analysis tool for post-processing of the model result (Mclane 2012). To examine the advantages of the AEM in the simulationoptimisation approach, a study was carried out for the Dore river basin in France. In this study, the AEM and FDM-based flow models were developed and coupled with the particle swarm optimisationbased optimisation model (Gaur et al. 2011).

In the Cauvery delta of south India, groundwater is used intensively because surface water bodies are insufficient to fulfil the water demand for domestic and irrigation needs. To find out the relationship between groundwater chemistry and the behaviour of the aquifer system on the local scale finite difference flow model (MODFLOW) was studied (Vetrimurugan et al. 2013). Coastal aquifers along the Chennai city are under stress due to excess groundwater pumping. A model was developed using groundwater modelling system (GMS) to understand the behaviour of the aquifer with the changes in hydrological stresses (Elango and Sivakumar 2008). Excessive withdrawal of groundwater without having proper planning of water recharge becomes the cause of rapid depletion of groundwater in the Ganga river basin. Groundwater modelling was performed for the Ganga river basin through a regional scale model (Maheswaran et al. 2016); although no significant work has been performed for the middle part of the Ganga river basin which is one of the most densely populated areas in the world.

In this paper, a groundwater modelling is performed to understand the dynamics of groundwater resources. The groundwater models are developed using the AEM and FDM and comparison was done based on the results obtained including limitations and benefits of both the models.

\section{Study area}

The study area is the part of the Ganga river basin which lies in the state of Uttar Pradesh and bounds between two major rivers the Ganga and Gomati rivers. The river Ganga lies in the southern and eastern part of the study area and Gomati river lies in the northern part. Administratively, the study area covers three districts; Varanasi, Sant Ravidas Nagar and some areas of Jaunpur and the total area of study is $\sim 2785 \mathrm{~km}^{2}$. The study area lies 
between latitude $25^{\circ} 05^{\prime} 20^{\prime \prime}-25^{\circ} 40^{\prime} 01^{\prime \prime} \mathrm{N}$ and longitude $82^{\circ} 22^{\prime} 05^{\prime \prime}-83^{\circ} 11^{\prime} 35^{\prime \prime} \mathrm{E}$ as shown in figure 1 .

The study area undergoes a humid subtropical climate with a large variation of temperature during summer and winter. The entire year can be divided into four seasons. The time between the mid-November to the first week of March is the winter season. The summer season which follows continues up to the June end. The duration of the rainy season is approximately 3 months July to the middle of October. The temperature variation during the summer goes from $30^{\circ} \mathrm{C}$ to $46^{\circ} \mathrm{C}$, and in winter temperature may fall below $5^{\circ} \mathrm{C}$. The monthly rainfall varies over an area in the range of 96-290 $\mathrm{mm}$. The maximum rainfall is recorded in July. The average annual rainfall over the area is around $1100 \mathrm{~mm}$, but in the last few years it reduces. The drainage of the study area is controlled by two main rivers Ganga and Gomati which flow from west to east. Both rivers are perennial and meandering in nature.

Continuously increasing water demand at domestic, agriculture and industrial levels is increasing the pressure on the groundwater resource of the study area. Proper planning and management strategies can help to deal with this problem, and groundwater models are the best tools for finding the future scenarios and assessment of management strategies before their implementation on the real field.

\section{Data used: Digital elevation model (DEM) generation and shapefile creation}

Before starting the development of the model, data were collected through different modes. In this study, satellite imagery was used for the preparation of the (DEM and the land use and land cover (LULC) map (https://earthexplorer.usgs. gov). Elevation varies from 33 to $101 \mathrm{~m}$ above the mean sea level (MSL) which shows that topography does not have a significant variation in the elevation level. Shuttle Radar Topography Mission (SRTM) DEM data were used to know the ground surface characteristics. All data used in this study were projected to the World Geodetic System (WGS) 1984 of the global reference system and the Universal Transverse Mercator (UTM) Zone-44N coordinate system was used (https://

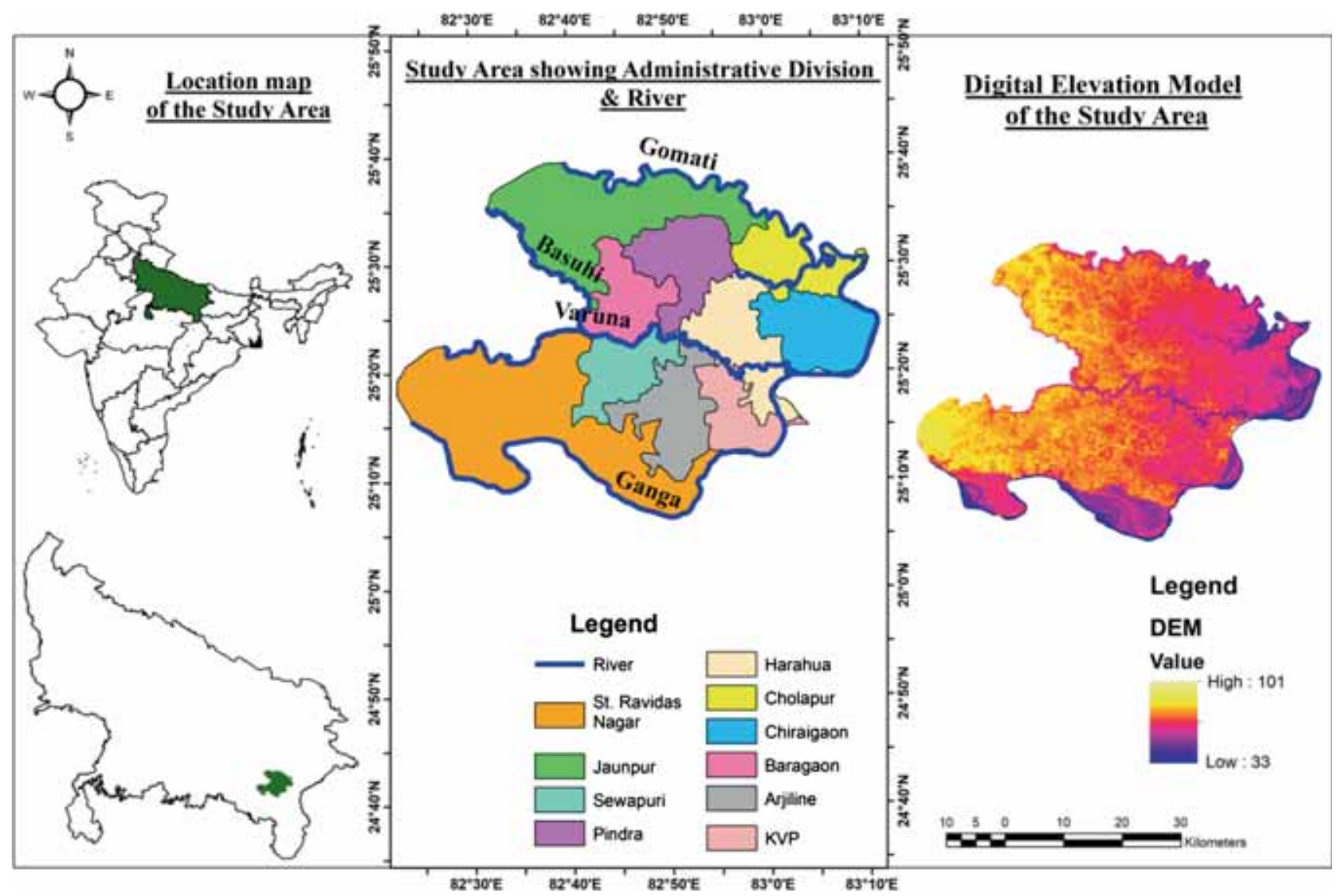

Figure 1. Location map of the study area along with rivers and DEM. 
earthexplorer.usgs.gov). The Ganga river has an average elevation of $66.27 \mathrm{~m}$ from MSL at the upstream side near the city Pali with coordinates of $82^{\circ} 23^{\prime} \mathrm{E}$ and $25^{\circ} 16^{\prime} \mathrm{N}$, where it enters into the study area and an average elevation of $60.78 \mathrm{~m}$ at the downstream side situated near the town of Chaubepur with coordinates of $83^{\circ} 10^{\prime} \mathrm{E}$ and $25^{\circ} 31^{\prime} \mathrm{N}$. The elevation of Gomati river from the upstream to downstream side ranges from 68.32 to $60.78 \mathrm{~m}$ MSL with the coordinate values of $82^{\circ} 39^{\prime} \mathrm{E}$, $25^{\circ} 39^{\prime} \mathrm{N}$ and $83^{\circ} 11^{\prime} \mathrm{E}, 25^{\circ} 31^{\prime} \mathrm{N}$, respectively.

The data input, which is needed, for the model development, was created in the geographic information system (GIS) environment. River boundaries, the location of pumping and recharge wells, recharge layer and other shapefiles were produced in ArcGIS 10.1. Figure 1 shows the river location and the DEM of the study area. LULC information was obtained using LANDSAT 8 satellite imagery which was downloaded from the United States Geological Survey (USGS) website. Supervised image classification was done using a maximum likelihood classifier technique. The LANDSAT 8 satellite image has 11 bands, and in the study, 3 bands were used, i.e., Band 5 (B5), Band 4 (B4) and Band 3 (B3). These three bands were stacked using image processing software, and area of interest (study area) was delineated. As per LULC information, St. Ravidas Nagar has the maximum agricultural area followed by Jaunpur. Kashi Vidya Peeth block has the minimum vegetation cover. All blocks of the study area have a minimum coverage of water feature class.

\section{Methodology}

\subsection{Model development using the FDM approach}

Two approaches can develop a groundwater flow model one is the grid approach and second is the conceptual model approach. The grid approach involved working directly with the threedimensional grid and applying sources/sinks along with different model parameters on a cell-by-cell basis, whereas the conceptual model approach includes the delineation of different hydrogeological features and boundary conditions using different elements based on the GIS. The grid approach was useful for the simple and small area while for the complex groundwater system conceptual approach was used. Once the conceptual model was created, it was transferred into the grid to perform the numerical solution. In this study, initially, a conceptual model was developed for the study area. The model domain covered an area of $2785 \mathrm{~km}^{2}$ with a grid size of $250 \times 250 \mathrm{~m}$ with three layers. Therefore, in the model, around 1,38,000 grid cells were taken for the numerical solution which increased the complexity and computational runtime for the model. The top layer of the model was defined by elevation data obtained through SRTM DEM (DEM data were imported in ASCII file). The interpolation was done using scatter points created from DEM and feature files available in the dataset in GIS.

Another most important part was to define the model boundary conditions. The two rivers, i.e., Ganga and Gomti were taken to define the constant head boundary of the study area whereas specified flow boundary conditions were defined at two places. Figure 1 shows the river as a boundary in the study area, and west and north-west and open part were considered as specified flow boundary. Specied flows were defined based on previous groundwater level data which were taken from the Central Ground Water Board (CGWB) and field data collection. Once the groundwater contours were generated, the flow rate was quantified based on it. And it was further finalised through the model calibration process and was taken as $0.00055 \mathrm{~m}^{3} /$ day. The sensitivity analysis study was performed for this specified flow value. In the sensitivity analysis, by varying the specified flow value, less variation in the model results was found. Therefore, the finalised value was found close to the true value. River crosssection data were collected through field survey whereas river head data were taken from the Central Water Commission (CWC) and field survey. Differential global positioning system was used for the measurement of elevation data. The initial groundwater head at different locations was obtained from the India-WRIS (Water Resource Information System of India) portal for 2005 (http://www.india-wris.nrsc.gov.in). All data were collected for a pre-monsoon and post-monsoon seasons. The pre-monsoon groundwater level was observed at 1.5-20 m below the groundwater level over the study area. These fluctuations can be observed from the India-WRIS portal (http:// www.india-wris.nrsc.gov.in).

\subsection{Model parameters}

The major source of groundwater recharge is precipitation and irrigation return flow. After generating the surface runoff through rainfall, the 
remaining part of the rainfall water infiltrates into the ground and recharges the aquifer. The recharge rate was calculated by considering all the parameters which influence the groundwater infiltration into the surface (Cherkauer 2004; Obuobie 2008) such as soil and land use. The recharge rate for the study area is computed based on the land-use map generated through a satellite imagery and soil map.

The discharge from the groundwater was calculated by computing the total water demand for the study area. Total groundwater discharge for the area was calculated by accounting the total water consumption by inhabitants, industry, agriculture and livestock. Water demand was calculated for the inhabitants of the study area by considering the average per capita demand for $170 \mathrm{l} /$ person/day (Modi 1998). The industrial water demand was calculated by taking the water consumption for each industry and type of industry. The industrial data were obtained from the Central Pollution Control Board (CPCB). The livestock water demand was also calculated by taking average drinking water demand for cows, buffalos, goats, pigs, sheep and poultry that is $30,35,3,3.5$ and 11 /day, respectively (http://upenvis.nic.in). Total water demand for the study area was found through adding each demand. For the calculation of the number of the wells in the study area, this total water demand was divided by the aquifer maximum yield capacity which was taken as 10 litres per second (lps).

Evapotranspiration was another parameter which affects the groundwater to some degree. It is the total water lost because of the combined effect of evaporation from the soil and transpiration through the plant leaves. Direct measurement of the actual evapotranspiration is difficult; hence it is usually estimated from the potential evapotranspiration (PET). PET was calculated using the Priestley-Taylor method. This can be used in non-agricultural and forested areas to drive actual evapotranspiration and in water balance calculations (Priestley and Taylor 1972). For cultivated areas evapotranspiration was estimated using the Hargreaves method (Hargreaves and Allen 2003) and for radiation energy balance reference was taken from Allen et al. (1998). The estimated evapotranspiration value for the study area was taken as $0.00002 \mathrm{~mm} /$ day.

\subsection{Model calibration}

Model calibration is the post-process part of the model development. In this study, model parameters are adjusted within the limits of the uncertainties to get the model replica of the actual system that satisfies the already agreed criteria. The model calibration was done using the parameter estimation tool (PEST). The PEST includes the modification of the input parameter values to bring upon the closet agreement between the modelled and observed water heads. In calibration, $1.0 \mathrm{~m}$ threshold value for the groundwater head was taken. The simulated head for most of the observed wells was considered acceptable if their distinction with the marked head was equivalent or not exactly $\pm 1.0 \mathrm{~m}$. The parameters that were taken for the adjustment were hydraulic conductivities and recharge rates. Fourteen observation points/wells were chosen for the calibration purpose. Figure 2 shows the location of the 14 observation wells. These points were well scattered over the study area with the known observed groundwater heads. After the model development, the initial results show the high-groundwater head as compared to the marked head, which indicates that there is need to adjust the recharge rate. Table 1 shows the values used for the adjustment of the model. During the calibration process, the recharge value was changed in the pre-defined model domains. After fixing the recharge rate, the next step is to adjust the hydraulic conductivity. Hydraulic conductivity was improved by obtaining an answer with the best understanding between the observed and simulated groundwater heads.

\subsection{Model development using the AEM approach}

AnAqSim uses the AEM to perform groundwater modelling. For conceptualisation of the study area, the base-map file was created in the DXF format in a GIS environment which includes river, discharge well and the boundary of the study area. The model domain was defined before inputting any model parameters. In AnAqSim, the term domain is referring to the regions within which the aquifer properties are constant.

\subsection{Boundary conditions}

In the AEM, boundary conditions are defined in the hydrological element itself as the head. Head specified boundary consists of river Ganga, Gomati and Basuhi as shown in figure 1. Digitisation of the head specified boundary was done in a counter-clockwise direction starting from 


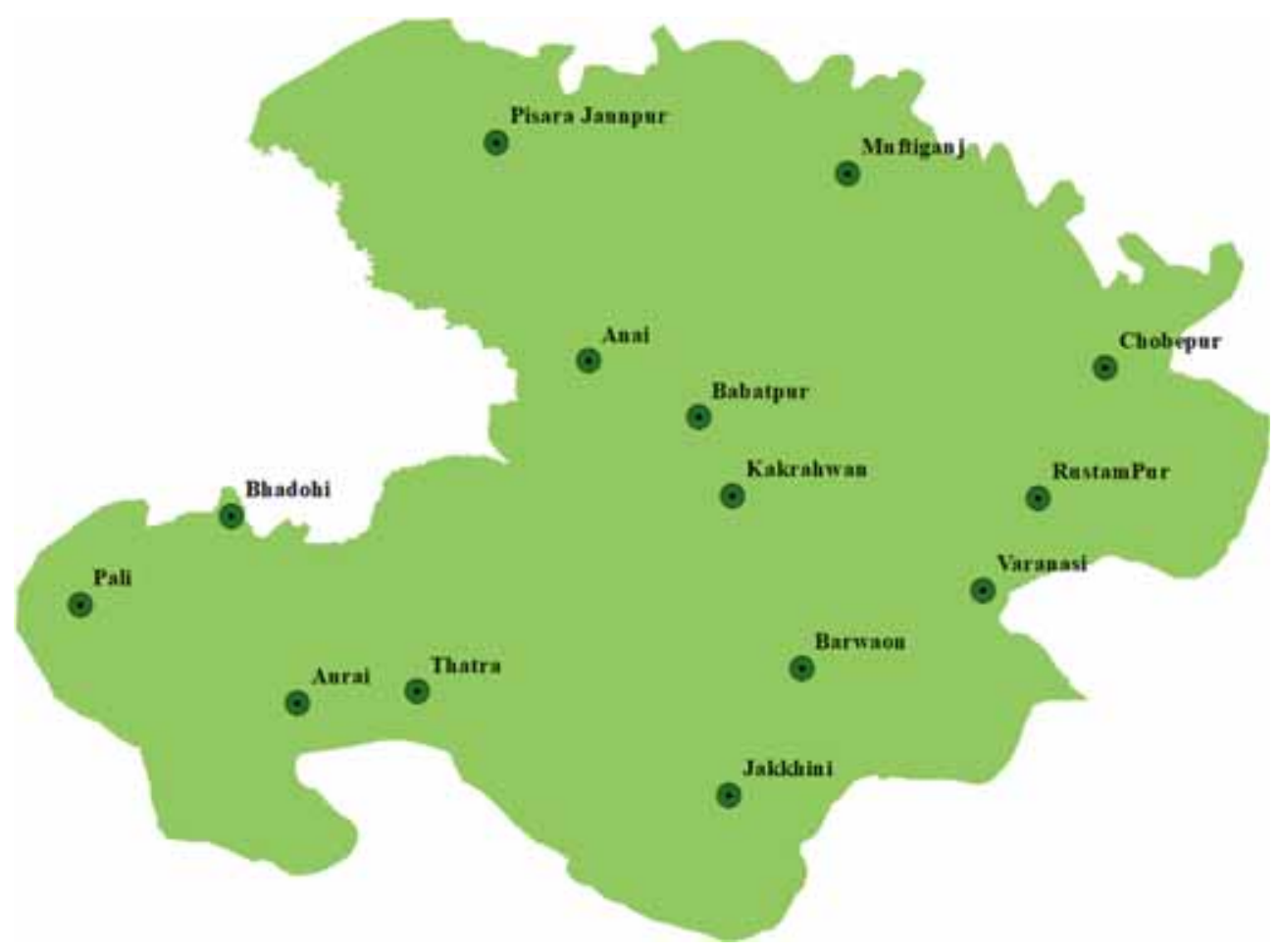

Figure 2. Location map of the observation wells taken in the study.

Table 1. Model parameters used in the calibration with their values.

\begin{tabular}{llc}
\hline & \multicolumn{1}{c}{$\begin{array}{c}\text { Recharge } \\
\text { value }\end{array}$} & $\begin{array}{c}\text { Hydraulic } \\
\text { conductivity }\end{array}$ \\
\hline Initial run & $8 \times 10^{-5}$ & 8 \\
Run 1 & Initial $\times 10$ & 10 \\
Run 2 & Initial $\times 100$ & 14 \\
Final selected & 0.008 & 18 \\
$\quad$ value & & \\
\hline
\end{tabular}

Ganga and end with Basuhi river. The far-field flow was taken as $0.005 \mathrm{~m}^{3} /$ day.

\subsection{Recharge and discharge well}

The recharge rate was taken same as the MODFLOW model. The recharge rate was considered to be uniform over the study area. The value of the recharge rate was taken $\sim 0.008 \mathrm{~m} /$ day.

The discharge wells were developed in ArcGIS, imported to excel and pasted in AnAqSim software. The value of good discharge was taken from the GMS which is $-1728 \mathrm{~m}^{3}$ /day (negative sign indicates the extraction of the groundwater). By changing the discharge rate (increase or decrease), an effect on the groundwater level can be noticed.

\subsection{AEM model calibration}

AnAqSim software has a feature to check the line boundary conditions at any point or line in the study area. Here, head at the boundary line along Ganga river was checked in the upstream and downstream sides. Figures 3 and 4 show that the value of the model head is close to the specified head, but it varies along the segment. The modelled head exactly matches at six points with the specified head. There were six control points where equation can be written to achieve a specified head.

\section{Results and discussion}

From the model, the groundwater head at every point was obtained. This groundwater level symbolises the real groundwater aquifer system, which will be performing as actual aquifer system under various stresses. Figure 5 shows the simulated groundwater head obtained from the model in the contour form.

The accuracy of this simulated groundwater head can be verified through the validation process. The results of the validation process are presented in figures 6 and 7 . Figure 6 shows the graph between observed heads and the simulated heads 


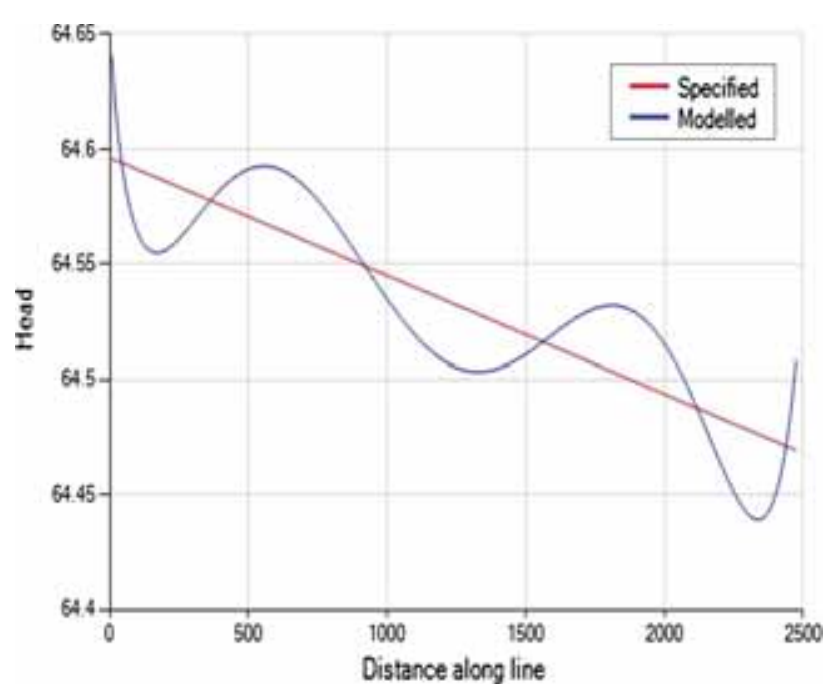

Figure 3. Head boundary conditions at upstream of the Ganga river.

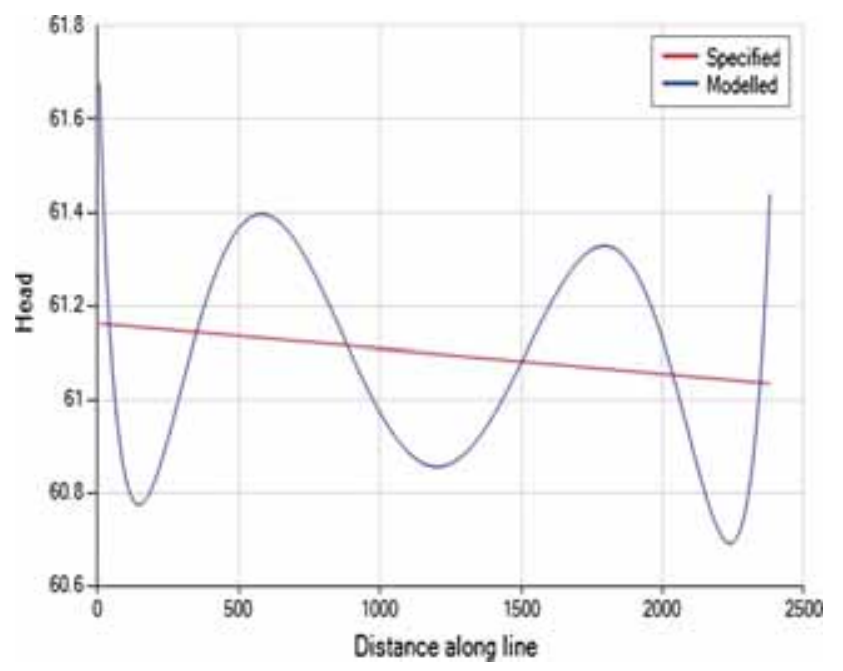

Figure 4. Head boundary conditions at downstream of the Ganga river.

computed using a groundwater flow model at the location of observation wells, after the model calibration. From the graph, it can be observed that the maximum number of points is positioned close to the best fit line which shows a good agreement between the observed head and simulated head. In the graph, there are some points which are far from the diagonal line introducing some errors in the model. The reason for this deviation of the head data from the actual head may be due to some inaccuracy in the data collection.

A residual vs. observed value plot is shown in figure 7. A residual is calculated by the difference in the observed head and modelled (computed) head. This plot is used to show how well the entire set of observed values matches a model solution. As shown in figure 7 , the trend of the solution values with regard to matching the observed data was analysed. It shows that the maximum number of wells close to zero residual lines which shows that the model is behaving like an actual groundwater system.

Figure 8 shows the graph between the observed head vs. modelled head. This graph is developed in AnAqSim software which indicates that the modelled head is greater than the observed head. But at some points the modelled head is equal to the observed head.

The results produced by both methods were compared on the basis of boundary conditions, data used and model development. It was found that in the FDM, the mathematical approximation is used in solving the groundwater flow equation while in the AEM harmonic function is used to solve the groundwater flow equation (Laplace equation) which produces more accurate results. Due to the presence of an alluvium aquifer in the Ganga river basin, the development of the AEM model was observed very fast with the desired accuracy. As the AEM provides a continuous groundwater level surface while the FDM provides solutions at discrete points in the grid, the AEM approach is suitable to follow the sharp changes of the groundwater level while the FDM approach provides the groundwater surface only at discrete points/grids. At the places of sharp variation of the groundwater level, the grid must be dense to map the accurate groundwater level which creates the complexity in the model. In the AEM, it is feasible to tackle the confined and unconfined aquifers the same way due to the application of discharge potential. It is a very positive aspect, in the case of uncertainty like the extent of a confined and unconfined aquifer is unknown, or subject to changes in the case of different situations. While the basic equation used in the FDM approach contains the term of transmissibility, i.e., different in the case of a confined or unconfined aquifer. Although there are some tools available for the solution of this problem, it needs too much care and sophistication in the development phase of the model.

The FDM is more rigid under the boundary conditions. It needs to fix boundaries, and each boundary must be defined properly. While in AEM there is no obligation for the fix boundary 


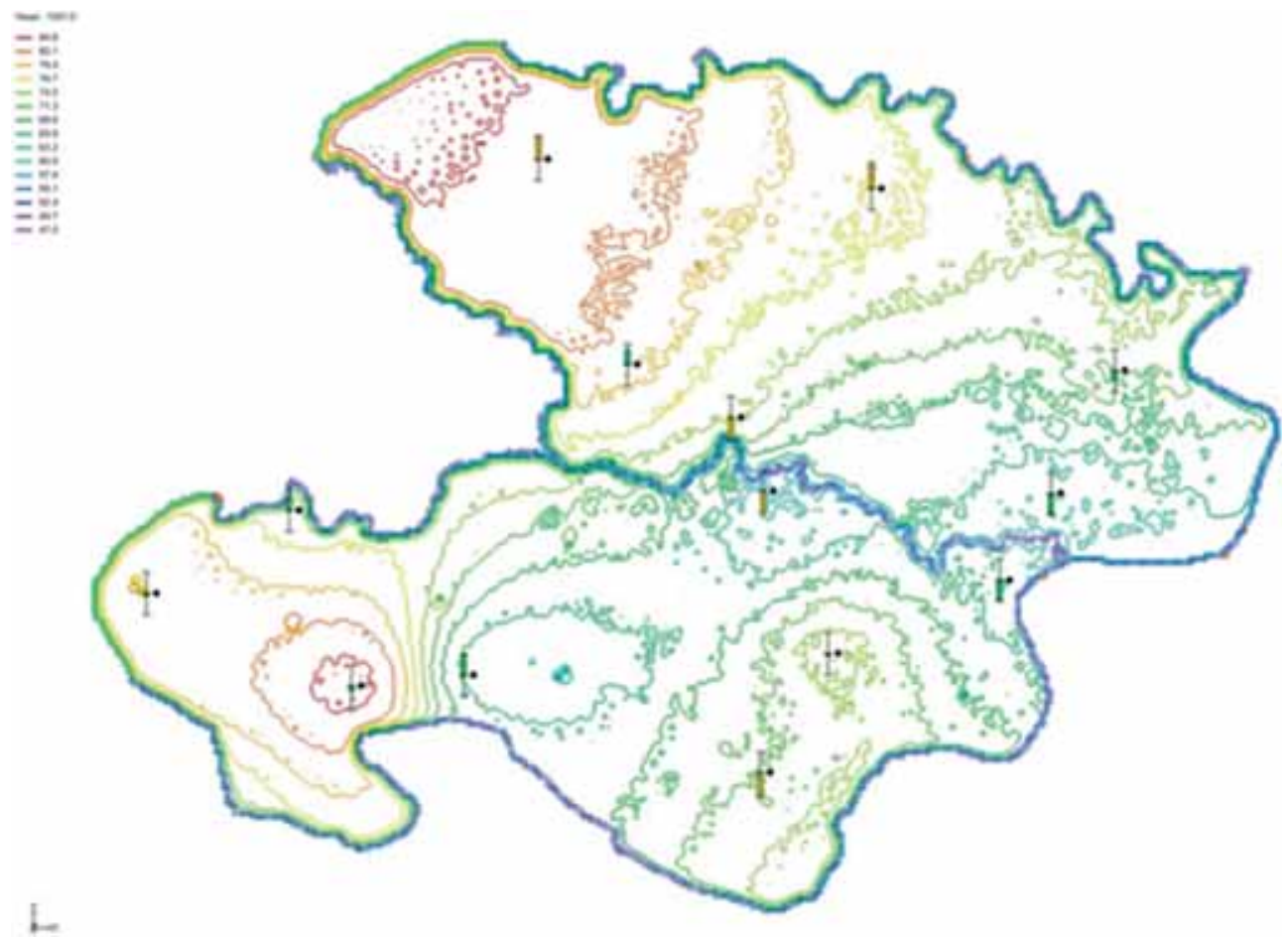

Figure 5. Simulated groundwater head for the study area in a grid form.

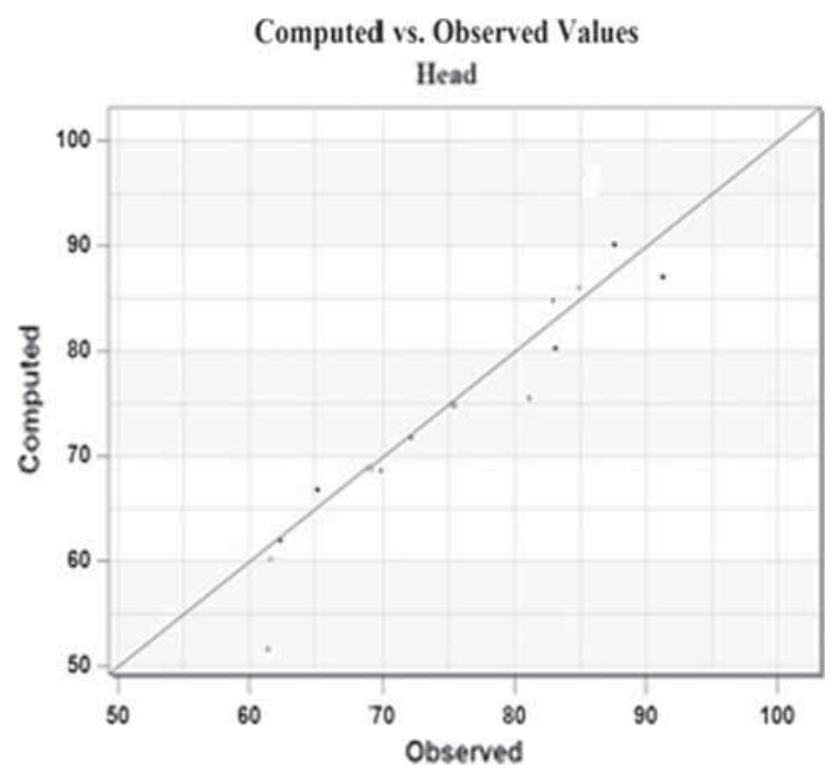

Figure 6. Observed head vs. computed head (in $\mathrm{m}$ ).

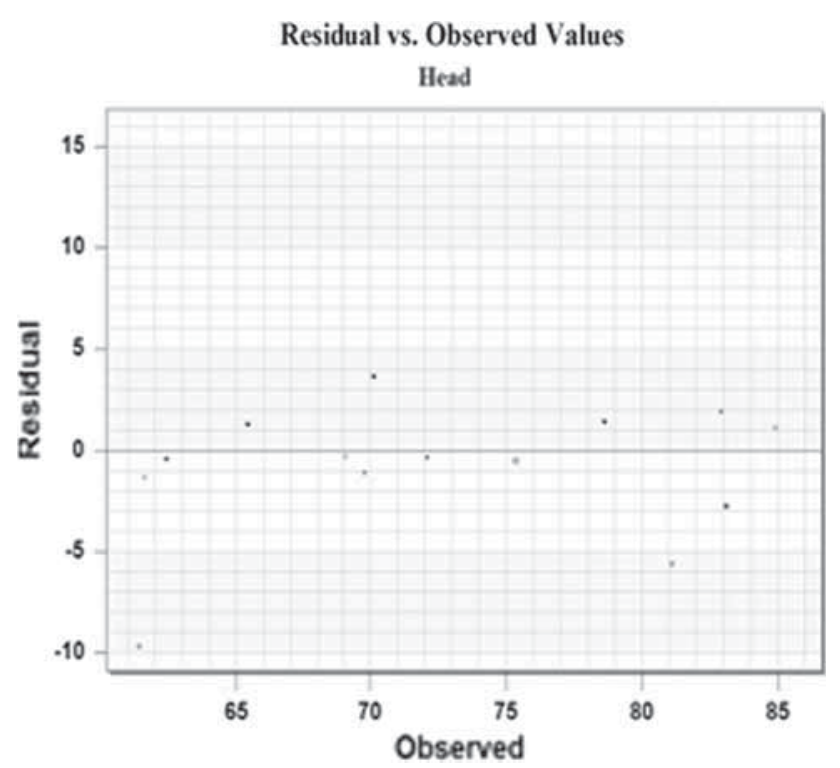

Figure 7. Observed head vs. residual (in m). conditions. It was found that the AEM model is very efficient to develop the local small size model of Varanasi city out of large model for the river basin. In AEM, the selection of solution points for the local desire area can be defined directly instead of generating the solution for the whole model domain which shows that AEM-based modelling is less complicated and less time consuming. AEM modelling is found competent to position the wells more accurately in the domain. In the FDM, the transformation is required of geological and hydro-geological maps to a uniform data set. It requires a larger amount of data which are connected to the grid points. 


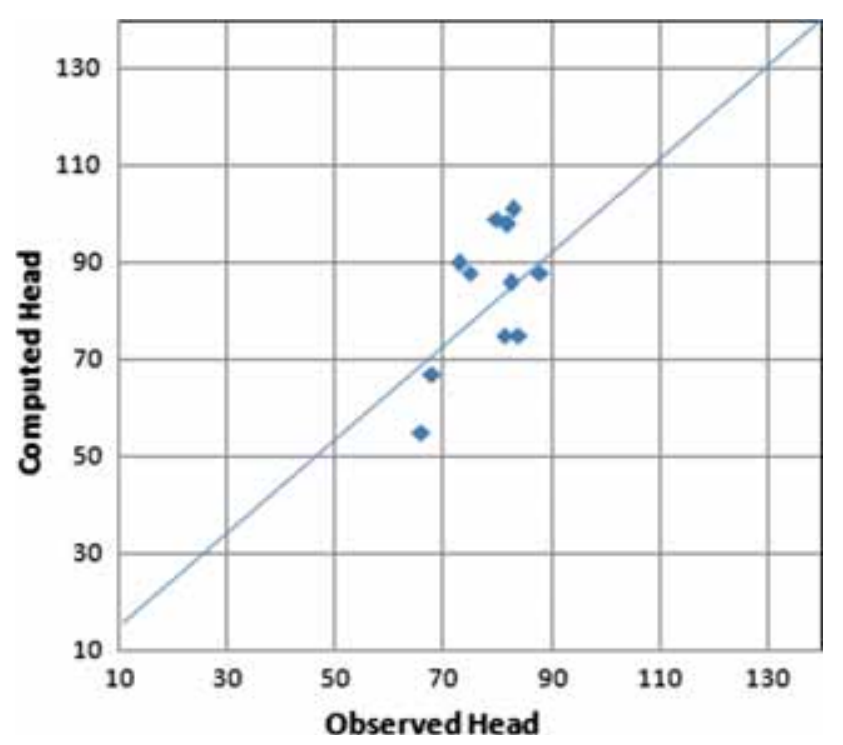

Figure 8. Observed head vs. modelled head.

the FDM as it is not yet completely developed in AEM mode. The AEM approach should be adopted if the aquifer boundary conditions are not well defined or approximations under boundary conditions are not possible. For a large and complex area the AEM should be chosen for quick model development as in FDM it becomes very difficult to collect a large number of input data for the whole domain.

\section{Acknowledgements}

The authors would like to acknowledge the support of the Department of Civil Engineering, IIT (BHU) Varanasi, India. We are also thankful to our lab staff of the department, who spent extra time helping us for the field survey. We highly appreciate the efforts of anonymous reviewer for his constructive comments to improve the manuscript.

\section{Conclusions}

Groundwater modelling is very important to understand the dynamics of groundwater behaviour and correspondingly it can be used as a tool to identify the best management practices for groundwater resource conservation. In this study, groundwater modelling was performed for the middle part of the Ganga basin near Varanasi and adjoining areas by two accepted methods of the groundwater modelling, i.e., FDM and AEM. The FDM-based model was developed using MODFLOW, and the AEM model was developed using AnAqSim. The two methods were compared during the process of model development. The results of the models show that AEM solutions were more accurate than the FDM solutions as AEM is based on the harmonic function which gives continues solution over the domain. The AEM was found more efficient and less complex regarding the fast conceptualisation of models due to less complex data entry. Although both methods were very useful and highly accepted among groundwater professionals, the requirement of the given problem can help to decide which method to be used. The study concluded that the FDM approach should be adopted if, aquifer layers are not horizontal and they are non-homogeneous in nature or approximation in the permeability value is not possible. Also, in the case of the FDM, well-defined boundary conditions should be known with suitable head values. Also, transient modelling is preferable in

\section{References}

Allen R G, Pereira L S, Raes D and Smith M 1998 Crop evapotranspiration: Guidelines for computing crop water requirements; FAO Irrigation and Drainage Paper 56, Rome, Italy.

Bakker M 2004 Transient analytic elements for periodic Dupuit-Forchheimer flow; Adv. Water Resour. 27 3-12.

Bakker M, Anderson E I, Olsthoorn T N and Strack O D L 1999 Regional groundwater modeling of the Yucca Mountain site using analytic elements; J. Hydrol. 226(3) $167-178$.

Bandilla K W, Igor J and Alan J R 2007 A new algorithm for analytic element modeling of large-scale groundwater flow; Adv. Water Resour. 30(3) 446-454.

Bennett G D 1976 Introduction to ground-water hydraulics; Techniques of water-resources investigations of the United States Geological Survey, Book 3, Chapter B2, 172 p.

Cherkauer D S 2004 Quantifying ground water recharge at multiple scales using PRMS and GIS; Groundwater 42 97-110.

Csoma R 2001 The analytic element method for groundwater flow modeling; Period Polytech.-Civ. 45(1) 43-62.

Elango L and Sivakumar C 2008 Regional simulation of a groundwater flow in coastal aquifer, Tamil Nadu, India; In: Groundwater Dynamics in Hard Rock Aquifers, Springer, Dordrecht, pp. 234-242.

Gaur S, Mimoun D and Graillot D 2011 Advantages of the analytic element method for the solution of groundwater management problems; Hydrol. Process. 25(22) 3426-3436.

Gorelick S M 1984 A review of distributed parameter groundwater management modeling methods; Water Resour. Res. 19(2) 305-319.

Haitjema H M, Kelson V A and Luther K H 2000 Analytic element modelling of ground-water flow and high performance computing; Environmental Research Brief EPA/ 600/S-00/001/, US Environmental Protection Agency. 
Hargreaves G H and Allen R G 2003 History and evaluation of Hargreaves evapotranspiration equation; J. Irrig. Drain. Eng. 129(1) 53-63.

Hunt R J, Anderson M P and Kelson V A 1998 Improving a complex finite difference groundwater flow model through the use of analytic element screening model; Groundwater 36(6) 1011-1017.

Kraemer S R, Haitjema H M and Kelson V A 2004 Working with WhAEM2000: A source water assessment for a glacial outwash well field; Vincennes, Indiana, US EPA, Office of Research and Development Report EPA/600/R-00/022, US EPA, Cincinnati, Ohio.

Maheswaran R, Khosa R, Gosain A K, Lahari S, Sinha S K, Chahar B R and Dhanya C T 2016 Regional scale groundwater modelling study for Ganga River basin; $J$. Hydrol. 541 727-741.

Matott L S, Rabideau A J and Craig J R 2006 Pump-and-treat optimization using analytic element models; Adv. Water Resour. 29(5) 760-775.

Mclane C 2012 AnAqSim: Analytic element modeling software for multi-aquifer, transient flow NGWA; Groundwater 50(1) 2-7.

Modi P N 1998 Water supply engineering, Standard Book House, Delhi.

Corresponding editor: N V Chalapathi RaO
Obuobie E 2008 Estimation of groundwater recharge in the context of future climate change in the White Volta River Basin, West Africa (Ecology and Development Series No. 62).

Olsthoorn T N 1999 A comparative review of analytic and finite difference models used at the Amsterdam water supply; J. Hydrol. 226(3) 139-143.

Omar P J, Soni R, Shivhare N, Dikshit P K S, Dwivedi S B and Gaur S 2017 Groundwater modelling study for Kashi Vidya Peeth, Varanasi, UP, India; In: 7th international groundwater conference on 'Groundwater Vision 2030: Water Security, Challenges $\&$ Climate Change Adaptation', NIH Roorkee \& CGWB India.

Priestley C H B and Taylor R J 1972 On the assessment of surface heat flux and evaporation using large-scale parameters; Mon. Weather Rev. 100(2) 81-92.

Strack O D L 1989 Groundwater Mechanics; Prentice Hall, Englewood Cliffs, New Jersey.

Strack O D L 1999 Principles of the analytic element method; J. Hydrol. 226 128-138.

Strack O D L 2003 Theory and applications of the analytic element method; Rev. Geophys. 41(2) 1005.

Vetrimurugan E, Elango L and Rajmohan N 2013 Sources of contaminants and groundwater quality in the coastal part of a river delta; Int. J. Environ. Sci. Technol. 10(3) 473-486. 